\title{
Memory for objects and parts
}

\author{
CORLENE ANKRUM and JOHN PALMER \\ University of Washington, Seattle, Washington
}

\begin{abstract}
Performance on whole comparisons of two whole objects was compared to that for partial comparisons of a whole object and a part. In particular, same-different comparisons were measured for sequential displays of two-dimensional line figures. The comparisons were analogous to those in the word priority paradigm (Johnson, 1975). The whole comparisons were found to be more accurate and faster than the partial comparisons. This whole advantage was also found for accuracy using a two-alternative forced-choice procedure. This effect was found for brief displays of a single object and for longer duration displays of two objects. It was also found for three different sets of line figures. In contrast, the whole advantage was not found for unconnected figures. These findings were interpreted in the context of hierarchical representations of objects and parts.
\end{abstract}

In this paper, we examine the consequences of the whole-part relation on visual perception and memory. One goal of visual perception is to identify or recognize objects. Such recognition depends on a comparison of the representation of the object to representations in memory. An object must be represented in memory in such a way as to allow the representation to be efficiently compared with already-stored memories. Palmer (1974, 1977; see also Bower \& Glass, 1976) proposed that a critical element of such a representation must be the hierarchical relation between wholes and parts. Consider a simple line drawing of a house, consisting of a triangle on top of a square. For this object, a hierarchical representation might consist of the top node of the hierarchy containing the whole house, the first level down might consist of a node containing the triangle and a node containing the square, and the bottom level might consist of nodes containing the single line segments. The parts are subordinate to the whole but, like the whole, are explicitly represented as single nodes. Each node also has properties associated with it. This type of representation retains the information about the relation of each node or organizational unit to each other and to the whole.

Hierarchical representations are often included in theories of perception and recognition. For example, Navon $(1977,1981)$ proposed that analysis proceeds from global features to local features in a hierarchy determined by spatial relations (but see Kinchla \& Wolfe, 1979; Martin, 1979; Miller, 1981). Marr and Nishihara (1978) proposed that shape is described by a hierarchy of self-contained, three-dimensional primitive shapes, along with their spa-

\footnotetext{
We thank Steve Buck, Anthony Greenwald, Earl Hunt, Lester Krueger, Davida Teller, Mark Vande Kamp, Robert Proctor, Penny Yee, and two anonymous reviewers for commenting on earlier versions of this article. This work was supported in part by Public Health Service Grant RR-07096 awarded through the University of Washington Graduate School. Correspondence should be addressed to Corlene Ankrum, Department of Psychology, NI-25, University of Washington, Seattle, WA 98195 .
}

tial relations, and that recognition can occur at any level of the hierarchy. Hoffman and Richards (1984) proposed that the representation of a shape's component parts, together with their spatial relations, is compared with memory in an attempt to recognize the object. Part boundaries are determined by transversality, the concave discontinuity that occurs when two surfaces meet. In their theory, recognizing parts can lead to the recognition of the whole. Biederman (1987) proposed that all objects can be broken down into a set of simple volumetric components called geons. Combinations of these geons in their proper spatial relations form the object representations. Recognition can then occur when any or all of the geons or parts of geons and their spatial relations to memory are compared.

Whole-part relations have long been studied using linguistic stimuli, which have the attractive aspect of having obvious wholes and parts. There is no disagreement that the most natural and mutually exclusive parts of a word are its component letters. This special case of the part-whole relation has been extensively investigated by two paradigms. In studies using the word superiority paradigm (Reicher, 1969), letters were identified more quickly and accurately when they occurred as part of a word than when they occurred alone. In studies using the word priority paradigm (Johnson, 1975; Sloboda, 1976), words were identified more quickly than were single letters contained in the words. Previous studies have applied the superiority paradigm to nonlinguistic stimuli in the object superiority paradigm (Weisstein \& Harris, 1974), but none have directly used the priority paradigm with nonlinguistic stimuli.

\section{Word Superiority}

In studies using the word superiority paradigm, subjects were presented with a letter-string stimulus followed by a visual mask and then were tested on what letter was at a particular location in the string (Reicher, 1969; Wheeler, 1970). The test was a two-alternative forced choice between two letters. The critical manipulation was 
the form of the letter-string stimulus: a word, a string of unrelated letters, or a single letter. Subjects were more accurate at recognizing the correct letter if it was presented as part of a word than if it was presented among unrelated letters or alone, the word-letter effect. Thus, the hierarchical relation between words and letters enabled performance to be facilitated when the letter appeared as part of a word.

\section{Object Superiority}

Analogous to the word superiority paradigm is the object superiority paradigm (Weisstein \& Harris, 1974; Williams \& Weisstein, 1978). In this paradigm, subjects were presented with a stimulus figure, a mask, and then a forced-choice test of one of the component lines. By analogy to the linguistic stimuli, the individual lines correspond to letters and the whole figure corresponds to a word. The critical manipulation was the form of the stimulus figure: a connected, three-dimensional, line figure, or an unrelated set of lines. Subjects were more accurate at recognizing the correct line when it was presented as part of a connected figure than when it was presented among unrelated lines. Williams and Weisstein (1978) also found an object-line effect. When the stimulus figure was not masked, performance was better for the line in the context of the whole than performance for the line alone. Thus, like letters in words, the hierarchical relation between the object and lines enabled performance to be facilitated when the line appeared as part of an object.

\section{Word Priority}

In the word priority paradigm (Johnson, 1975; Johnson, Turner-Lyga, \& Pettegrew, 1986; Marmurek, 1977; Sloboda, 1977), subjects were shown a whole word, and they then determined whether it matched a predesignated word or whether it contained a predesignated letter. Therefore, the comparison was either between two words or between a word and a letter. These conditions can be referred to as a whole comparison or a partial comparison, respectively. These experiments differed from word superiority experiments by having whole comparisons and by not having letter-letter comparisons. They also did not use masking and yielded relatively few errors. The wholecomparison condition resulted in faster responses than did the partial-comparison condition, although there were no significant differences in error rates. The hierarchical relation between wholes and parts enabled performance on whole comparisons to be better than performance on partial comparisons.

\section{Object Priority?}

Nonlinguistic stimuli yield results analogous to the results of linguistic stimuli in the superiority paradigm. Does the same hold for the priority paradigm? If so, this would be further support for hierarchical theories that place an emphasis on the whole-part relation, regardless of what the wholes and parts are. Although the priority paradigm has not been directly applied to nonlinguistic stimuli, there are several studies that contain whole and partial comparisons.

Biederman, Ju, and Clapper (cited in Biederman, 1987) used line drawings of familiar objects to study how recognition was affected when objects were missing some of their parts. Subjects saw slides of objects that either were complete or were missing some of their parts. Errors and reaction times (RTs) increased as the number of parts missing from the object increased.

In the embedded-figures tasks (Reed, 1974; Reed \& Johnsen, 1975), the partial comparison was done in two ways, with either the whole or the part as the to-beremembered stimulus. In Reed and Johnsen's task, subjects judged whether one pattern was part of another. Subjects performed better when the part was shown first than when the whole was shown first. A whole comparison was not done in these experiments, although Reed and Johnsen (Experiment 3) did test memory for the whole objects by having subjects draw them after performing the whole-part task; all subjects correctly drew the whole patterns.

Whole-part comparisons were used by Palmer (1974, 1977,1979 ) to investigate the effect of part goodness on perceptual processing. In his part-verification tasks, subjects viewed sequential or simultaneous displays of two letterlike figures. Subjects judged whether a three-segment figure was part of a six-segment figure. When the parts and wholes were presented simultaneously, part-verification time was faster for parts rated high in goodness than for those rated as poor (Palmer, 1977). In another set of experiments (Palmer, 1974, 1979), the task was done sequentially, and both orderings of the partial comparison were used. Performance was better in the part-first condition; this difference was most pronounced for the pairs of figures and parts rated poor in goodness. In another experiment, the number of line segments comprising the parts was varied from one to six. Performance improved as the number of line segments in the part increased. The six-segment parts were equivalent to the wholes, so this was actually a whole comparison. Accuracy improved as number of line segments increased, but did not differ between the five-segment partial- and whole-comparison conditions. RTs for whole comparisons, however, were significantly faster than for all of the partial comparisons, including that using the five-segment part.

From these studies, Palmer (1977) proposed that an object is represented as a hierarchical structure in which the top node represents the whole object and its properties, whereas lower level nodes represent finer and finer parts of the object and their properties. Such a representation, when coupled with specific processing assumptions, has many predictions for visual memory. For example, topdown processing of a hierarchical representation would predict an advantage for whole objects over their parts in memory tasks, whereas bottom-up processing or parallel processing would not. The top-down prediction was supported in that the whole comparison done in Palmer's (1979) task was always faster than any comparison between a whole and a part of less than six line segments. 
This whole advantage is analogous to that found in the word priority experiments, in which performance on comparisons of two words was better than performance on comparisons of a word and a letter (Johnson, 1975).

\section{THE PRESENT STUDY}

We used the whole and partial comparisons of the priority paradigm to pursue differences in judgments of wholes and parts. To test for a general advantage for judgments of whole objects over their parts, the priority paradigm was chosen because it directly compares wholes and parts. Therefore, in the present experiments, subjects viewed a study stimulus followed by a test stimulus to which they made a same/different judgment. In the whole comparison, the study and test stimuli had equal numbers of line segments, whereas, in the partial comparison, the stimuli differed in the number of line segments.

If nonlinguistic stimuli consistently yield the same pattern of results as do linguistic stimuli in this paradigm, then performance on whole comparisons will be superior to performance on partial comparisons. Such a result would support the hierarchical hypothesis that whole objects are represented separately from and superordinately to their parts.

\section{GENERAL METHOD}

In these experiments, the subjects were presented with the study object or objects, followed after a brief interval by the test object or objects. The common method across experiments is described next. Deviations from this common method are described separately for each experiment.

\section{Subjects}

The subjects in each experiment were graduate students, faculty, or staff members at the University of Washington. Some subjects participated in more than one experiment. Except for the authors, each subject was paid for participation.

\section{Apparatus}

A schematic of the stimulus configuration is shown in Figure 1. All stimuli were controlled by a Hewlett Packard computer (Mod-

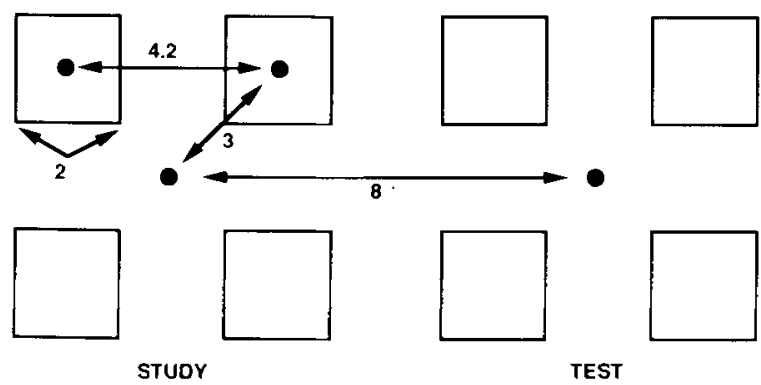

Figure 1. Schematic of display positions. Stimuli could appear within the area defined by each of the boxes. For some experiments, as shown, the study stimuli appeared on the left half of the screen, and the test on the right. Otherwise, the study and test stimuli appeared in the same locations, with the fixation point at the center of the quadrants defined by the boxes.

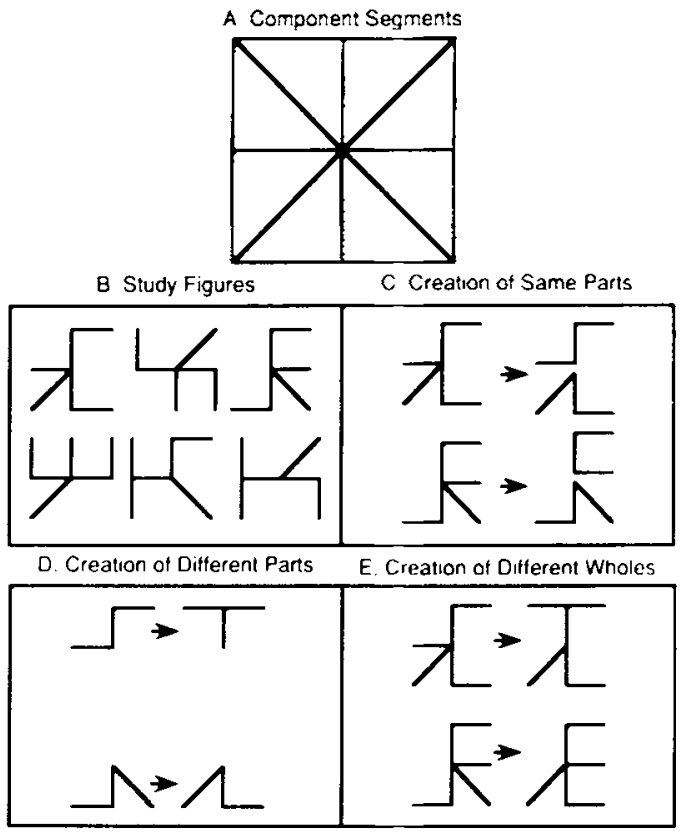

Figure 2. Set of figures used in Experiments 1, 3, 4, and 6. Panel A shows the component segments from which the stimull were constructed. Pand B shows the set of stx-egment whole figures. Paned C shows the creation of the set of same-part figures, created by dividing each whole figure into two mutually exchusive parts of three segments each. Panel D shows the creation of the dixtractor threesegment figures by changing one or two lines of a three-ecemeat part. Panel $E$ shows creation of the dbtractor sdx-segment foures by combining one three-segment component of a six-segmeat figure with the three-segment distractor for the other component.

el 9817) and were displayed on a 14-in. Hewlett Packard CRT (Model 35122). The CRT was indirectly illuminated to provide a background luminance of $3 \mathrm{~cd} / \mathrm{m}^{2}$. The intensity of the displayed lines had a luminance equivalent to $100 \mathrm{~cd} / \mathrm{m}^{2}$. (This equivalence was measured from a homogeneous display of the lines.) The greenish-tint P31 phosphor decays to $1 \%$ intensity at $0.25 \mathrm{msec}$ after display offset. The display was placed 15 in. in front of the subject; the stimuli subtended a visual angle of $2^{\circ} \times 2^{\circ}$. The stimuli could appear in any of four quadrants, each of which was centered $3^{\circ}$ from the fixation point. Figure 1 shows the configuration for the experiments in which the study stimuli appeared in the quadrants on the left side of the screen and the test stimuli appeared in the corresponding quadrants on the right side of the screen. In the experiments in which location was invariant between study and test, the quadrants were centered.

\section{Stimuli}

The stimuli used in Experiment 1 were a subset of those introduced by Palmer $(1974,1977)$ to study object perception. The possible line segments are shown in Figure $2 \mathrm{~A}$. The subset was generated by the following rules: (1) each stimulus must have one and only one diagonal, (2) each stimulus must have no enclosed parts such as triangles, and (3) each stimulus must be able to be broken into two parts of three connected lines each.

As shown in Figure 2B, a set of six figures was generated using these rules. Each of these figures was then divided into two mutually exclusive, three-segment connected parts, as shown in Figure $2 \mathrm{C}$. These three-segment figures comprised the same part test figures. Distractor test figures for each part were generated by mov- 


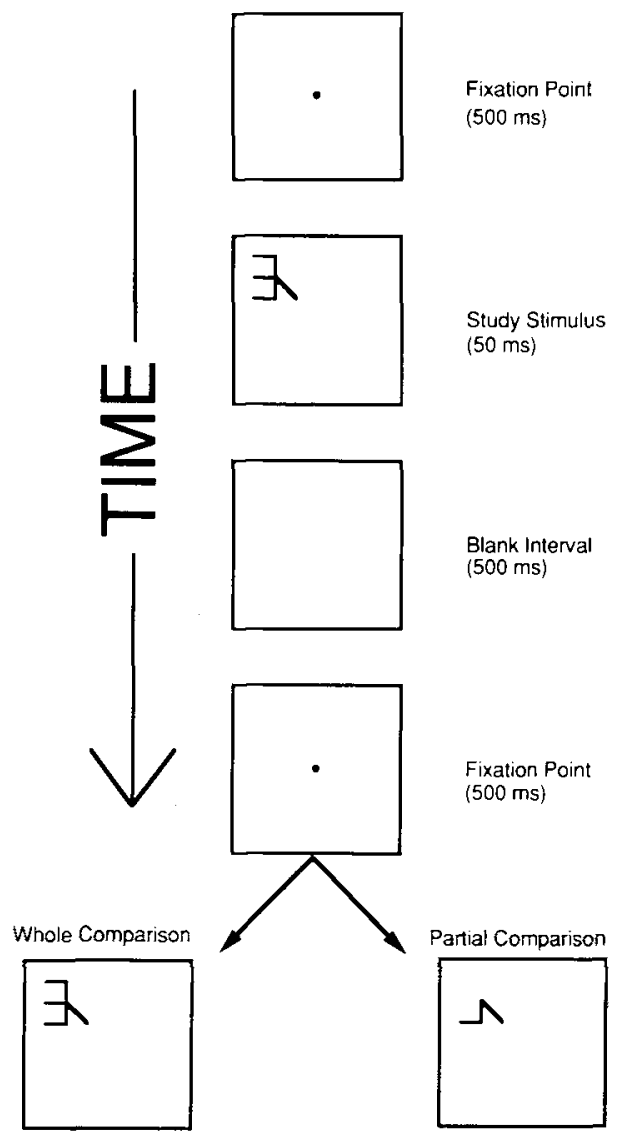

Figure 3. General procedure for a trial. Each trial began with the fixation point appearing for $\mathbf{5 0 0}$ msec, followed by the appearance of the study stimulus in one of the four quadrants around the fixation point, an interval when the screen was blank, the fixation point, and finally the test stimulus that remained on the screen until a response was made.

ing one or two line segments, as shown in Figure 2D, to create a different part. This set made up the distractors for the partial comparisons. Distractor test figures for wholes were made by combining one of each whole's component parts with the three-segment distractor for the other component, as shown in Figure 2E. This resulted in two distractor whole test figures for each study figure. This method of construction produced identical variations in the distractors for the whole and partial comparisons.

Each study stimulus appeared once in each of four rotations $\left(0^{\circ}\right.$, $90^{\circ}, 180^{\circ}$, and $270^{\circ}$ ). When more than one stimulus was displayed at a time, all were rotated the same amount. Mirror reflections of each item were also used, allowing eight versions of each stimulus. Within each trial, each test stimulus appeared in the same rotation and reflection as the study stimulus. The stimuli always appeared on a background grid of dots marking the stimulus's corners.

\section{Procedure}

A trial consisted of the following sequence, as shown in Figure 3. A fixation point appeared at the center of the possible stimulus locations for $500 \mathrm{msec}$. It disappeared, and the study stimulus or stimuli appeared for a fixed amount of time, followed by $500 \mathrm{msec}$ when the screen was blank. The fixation point then reappeared for $500 \mathrm{msec}$, immediately followed by the test stimulus, which remained on the screen until the subject responded by pressing one of two keys on a mouse. The left key was used for "same" responses, and the right key was used for "different" responses. The subjects were allowed to choose how to hold the mouse and which hand(s) or finger(s) to use in responding. No feedback was given during a 1-sec interval between trials.

The subjects were instructed to make a same/different judgment. For the whole-comparison condition, figures were to be judged "same" if and only if each line segment was an exact match between study and test. For the partial-comparison condition, a threesegment part was to be judged "same" if it exactly matched three segments of the whole study object. Unless otherwise specified, whole and partial comparisons were not presented in blocks. When more than one study stimulus was presented simultaneously, each test object was to be compared with the study object that had appeared in the same quadrant of the screen. Instructions to the subject emphasized both accuracy and speed of the response.

\section{Design}

There were equal numbers of same and different trials and equal numbers of whole and partial comparisons. In all experiments, stimulus item, rotation, and partial/whole comparison were counterbalanced.

\section{EXPERIMENT 1}

The purpose of the first experiment was to use the whole- and partial-comparison conditions of the priority paradigm to pursue the whole advantage for the nonlinguistic stimuli found in Palmer's (1979) study. A whole advantage is indicated by performance on whole comparisons between six-segment figures that is faster or more accurate than performance on partial comparisons between a six-segment figure and a three-segment figure.

\section{Method}

As shown in Figure 4, the study display was always a six-segment figure. In the whole-comparison condition, the test display was also a six-segment figure; in the partial-comparison condition, the test display was a three-segment figure. The study display appeared in one of the four quadrants on the left half of the screen; the test dis-

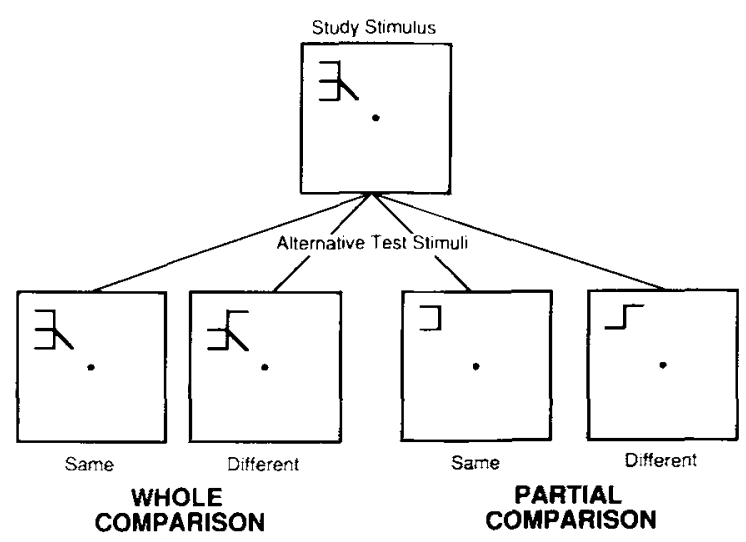

Figure 4. Conditions for Experiment 1. The study stimulus was always one six-segment figure. In the whole-comparison condition, the test stimulus was either the same six-segment figure or a distractor six-segment figure. In the partial-comparison condition, the test was either a three-segment part of the study stimulus or a threesegment distractor. 
play appeared in the corresponding quadrant on the right half of the screen. The study stimulus appeared for $50 \mathrm{msec}$. Whole and partial comparisons were mixed. Otherwise, the methodology followed the general methods described above. Twelve subjects participated in 96 trials each.

\section{Results}

Figure 5 shows the mean percent errors and mean correct reaction times for same and different stimuli in both conditions of Experiment 1. For both measures, the difference between whole and partial comparisons was reliable, with subjects performing better on the whole comparison than on the partial comparison. For percent errors, the mean difference across both same and different stimuli was $11 \% \pm 2 \%[t(11)=5.3, p<.001]$ and for correct RT the mean difference was $561 \pm 75 \mathrm{msec}[t(11)=7.5$, $p<.001]$.

Detailed results for all experiments are in Table 1. Performance measures are listed in Table 1 for separately for same and different stimuli. For each stimulus type, the table is subdivided by response type ("same" and “different").

The whole advantage was found for both same and different stimuli. For whole comparisons, the mean percent errors to same stimuli was $9 \% \pm 2 \%$; for partial comparisons, it was $24 \% \pm 4 \%$ (see Figure 5 and Table 1). This is a significant difference of $15 \% \pm 4 \%[t(11)=3.41$, $p<.005]$. For whole comparisons the mean correct RT for same stimuli was $962 \pm 99 \mathrm{msec}$; for partial comparisons, it was $1,549 \pm 129 \mathrm{msec}$, a significant difference of $587 \pm 45 \mathrm{msec}[t(11)=6.1, p<.001]$. For different

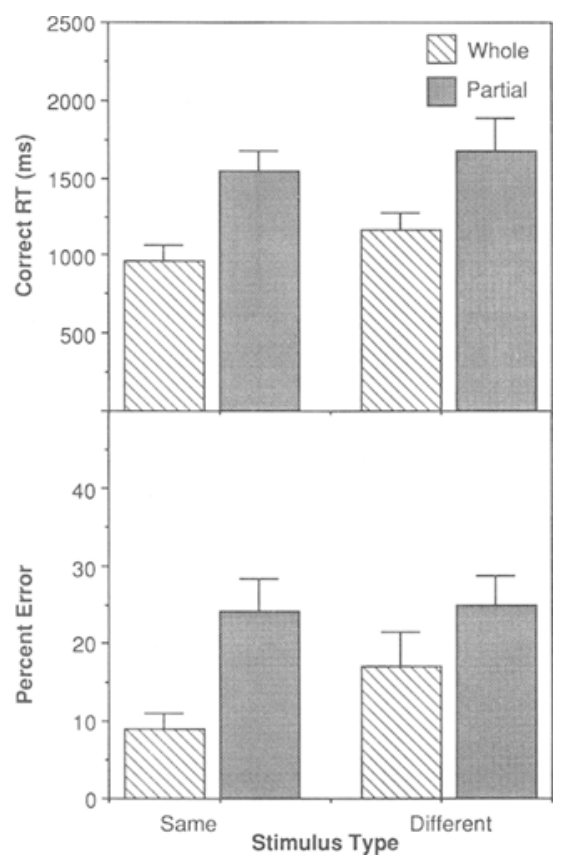

Figure 5. Experiment 1: Mean percent errors and correct RTs for same and different trials of whole and partial comparisons. Error bars indicate the standard error of the mean. stimuli, the mean percent errors for whole comparisons was $17 \% \pm 4 \%$, and it was $25 \% \pm 4 \%$ for partial comparisons (see Figure 5 and Table 1). This is a marginally significant difference of $8 \% \pm 4 \%[t(11)=1.7, p<.1]$. For different stimuli, the mean correct RT was $1,161 \pm$

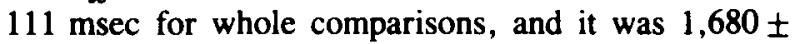
$208 \mathrm{msec}$ for partial comparisons, a significant difference of $519 \pm 128 \mathrm{msec}[t(11)=4.07, p<.005]$. Therefore, although the difference in accuracy for different stimuli was only marginally reliable between whole and partial comparisons, RTs were reliably slower for partial comparisons.

There were sufficient errors for error RTs to be accurately estimated in Experiment 1. The two kinds of errors are listed separately in Table 1. Error RTs were consistently slower than correct RTs. The mean difference was $256 \pm 99 \mathrm{msec}$ for the whole-comparison condition and $166 \pm 116 \mathrm{msec}$ for the partial-comparison condition.

The variability of RTs also differed across conditions, as shown in Table 1. Standard deviations were larger for partial comparisons than for whole comparisons. This increase was roughly proportional to the increase in mean RT. For example, the standard deviation for correct responses to same stimuli increased from $198 \mathrm{msec}$ for whole comparisons to $311 \mathrm{msec}$ for partial comparisons as the mean RT increased from 962 to $1,549 \mathrm{msec}$. The kind of response may also have had an effect on the standard deviations, but any such effect did not appear consistently across experiments listed in Table 1 .

Controls. Two replications of Experiment 1 were done, with 6 subjects each. In the blocked control, the stimuli were blocked by whole and partial comparisons. Again, the whole comparisons were more accurate [mean difference was $10 \% \pm 2 \%, t(5)=4.5, p<.005]$ and faster [mean correct RT difference was $487 \pm 95 \mathrm{msec} ; t(5)=$ $5.1, p<.005]$. Thus, the whole advantage occurs even when subjects can try to develop specialized strategies for part comparisons. In the no-grid control, the experiment was also replicated without the background grid that provided reference points for the position of the part. Again, whole comparisons were more accurate [mean difference was $16 \% \pm 3 \% ; t(5)=5.6, p<.005]$ and faster [mean correct RT difference was $386 \pm 112 \mathrm{msec}$; $t(5)=3.5, p<.01]$. Thus, the background grid was not essential in obtaining the effect.

\section{Discussion}

Whole comparisons were faster and more accurate than partial comparisons, replicating the whole advantage found by Palmer (1979). This was true for both same and different stimuli, for both mixed and blocked presentations, and for displays with and without reference points.

Accuracy bias. A first issue to consider is whether or not the whole advantage is due to bias. In this case, bias could arise due to the subjects' being more conservative about responding "same" to partial comparisons, relative to whole comparisons. It may be easier to respond "different" for partial comparisons, because they are not 
Table 1

Results of Experiments 1, 2, 3, 4, and 6

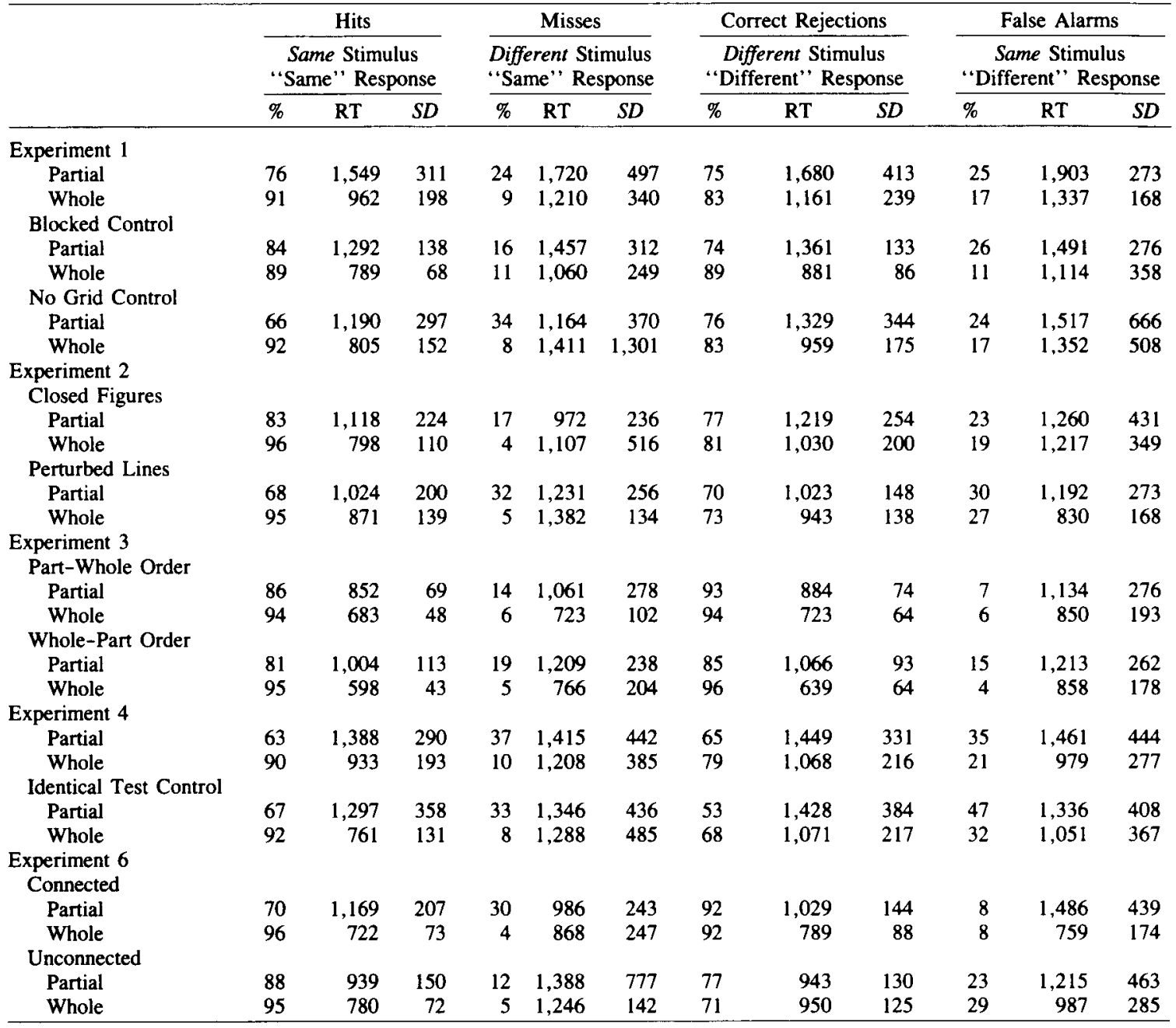

Note-RTs are given in milliseconds.

identical to the entire whole. This can be described using many models, such as Eriksen and Schultz's (1979) response competition model. This model states that evidence for a particular stimulus accumulates gradually over time due to a continuous flow of information about the stimulus. The "same" and "different" responses are primed as information accumulates. If the accumulation is biased toward "different" for partial comparisons, then the "different" response will be initially primed. For the present task, seeing a part as the test item may register some amount of evidence for "different" because it is not identical to the whole.

This possibility can be ruled out in three ways. First, there was little change in bias for whole versus partial comparisons. The percent "same" responses was 54\% $\pm 3 \%$ and $51 \% \pm 3 \%$ for whole and partial comparisons, respectively. This $3 \% \pm 4 \%$ shift is small, relative to the $11 \% \pm 2 \%$ change in percent error. Second, a conservative bias shift predicts that increases in one kind of error (false alarms) will be matched by decreases in the other kind of error (misses). This did not occur since errors for both same and different stimuli increased for partial comparisons, relative to whole comparisons. Third, the signal detection theory can be used to estimate the separate changes in sensitivity and bias. The bias parameter, $\beta$, did not change from whole comparisons (mean $\beta=$ $1.2 \pm 0.5$ ) to partial comparisons (mean $\beta=1.2 \pm 0.3$ ), whereas the sensitivity parameter, $d^{\prime}$, did change from whole comparisons (mean $d^{\prime}=2.5 \pm 0.1$ ) to partial comparisons (mean $d^{\prime}=1.6 \pm 0.2$ ). Thus, this parametric analysis confirms the nonparametric arguments. Clearly, the whole advantage is not due to bias.

Hierarchical representation. How does the hierarchical hypothesis predict the whole advantage found in Experiment 1 ? In Experiment 1, the study stimulus, being the only item on the screen, should have been perceived as an object. If this object is represented by a hierarchy such as the one described by Palmer $(1974,1977,1979$; 
see also Bower \& Glass, 1976), then that hierarchical representation would consist of a top node containing a representation of the whole object and lower level nodes containing finer and finer parts of that object. For example, the second level might contain representations of two three-segment parts of the whole, and the third level might contain separate representations of the six single line segments (in their proper orientations). It is assumed that this memory representation of the study stimulus is compared with a representation of the test stimulus. If the test stimulus is also a six-segment whole, then the comparison might only need to access the top node of each representation. If the two representations are exactly the same, then a "same" response is generated. If the two representations are very different, then a "different" response is generated. Only if the degree of certainty is not high enough to generate a response after comparing the top nodes will the rest of the hierarchy be searched. Therefore, judgments about whole comparisons can often be generated after accessing only the top node of the representation.

In a partial comparison, though, the judgment cannot be made as easily, because the representation of the study stimulus includes the whole as the topmost node. With top-down processing at comparison, partial comparisons require additional time to access the relevant lower node(s) in the representation of the study stimulus. Even if processing is not top-down, there still might be uncertainty about which level or which nodes within levels to access for the comparison. If the test part corresponds to an explicitly represented part in the study representation, a "same" response can be generated by finding the exact match for the test part in the study representation. If the test part does not correspond to a single node, a "same" response can still be generated if the part can be matched to explicitly represented component line segments in lower nodes. A correct "different" response for parts should occur only after an exhaustive search of the hierarchy. The data, although not conclusive, suggest that this might be the case. The correct "different" responses for partial comparisons take longer and are more variable than are those for whole comparisons (see Table 1). Partial comparisons will require more comparisons, on average, than will whole comparisons. Assuming each comparison takes time and has some chance of error, then partial comparisons mean more time and more errors than whole comparisons. By itself, Experiment 1 does not distinguish between the predictions of hierarchical representation and predictions based solely on the idea that partial comparisons include more uncertainty during access or retrieval than do whole comparisons, regardless of representation.

\section{EXPERIMENT 2 Other Stimuli}

In Experiment 1, we demonstrated the whole advantage for the single set of stimuli, derived from Palmer's (1977) letterlike stimuli that had no enclosed parts. Here, we test the generality of the effect by using two more stimulus sets. One is a set of two connected closed figures; the other is a set of perturbed lines that are much less letterlike than our original stimuli.

\section{Method}

The same procedure was used as in Experiment 1 (see Figure 4). There was a single study figure; the duration of the study was brief ( $50 \mathrm{msec}$ for the closed figures, and $250 \mathrm{msec}$ for the perturbed lines). These durations roughly equated performance for the two stimulus sets. Six subjects participated in 112 trials each.

Closed ngures. As shown in the top of Figure 6, these stimuli consisted of all the combinations of a triangle and a quadrilateral (enclosed parts) that fit within a square framework and were connected. Stimulus 4 was excluded because the parts are not connected, and Stimulus 7 was excluded because the two parts together formed a triangle. Thus, there were 14 stimuli. Each stimulus was shown in all possible combinations of rotation and mirror reversal. The distractors were formed by changing the orientation of either the quadrilateral or the triangle.

Perturbed lines. These figures were chosen as examples of a class of stimuli that do not have enclosed parts. These stimuli, as shown in bottom of Figure 6, were 10-segment connected line figures that were constrained to have five segments on each side of the center point and to have an orientation that was roughly diagonal. Two contiguous segments could be in the same orientation, yielding one longer segment. Distractors were formed by changing

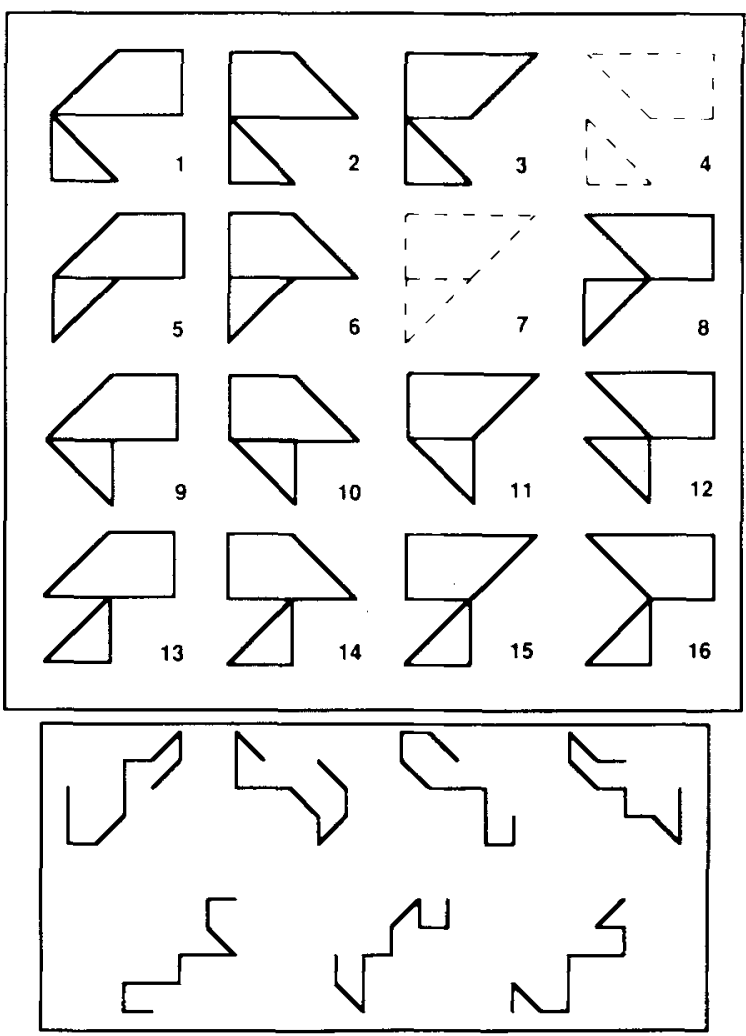

Figure 6. Stimuli for Experiment 2. The closed figures at the top were created by taking all the combinations of a triangle and a quadrilateral that fit within a square. Excluded from use were Stimulus 4, because the parts were not connected, and Stimulus 7, because the two parts together formed a triangle. The perturbed line figures at the bottom were composed of 10 line segments and were constrained to have five connected segments on each side of the center point and a roughly diagonal orientation. 
the orientation of one or two connecting line segments in one half of the original stimulus. The change could include changing the orientation of one segment of the longer two-segment straight lines.

Both the perturbed lines and the closed figure stimuli were superimposed on a set of dots that marked the corners of the stimulus display.

\section{Results}

Closed figures. As shown in the left panels of Figure 7, the subjects performed better on the whole comparison than on the partial comparison. The percent error mean difference $[8 \% \pm 5 \% ; t(5)=1.62, p<.1]$ was only marginally different, whereas the correct RT mean difference $[261 \pm 70 \mathrm{msec} ; t(5)=3.77, p<.01]$ was significantly different.

Perturbed lines. Results are shown in the right panels of Figure 7. For both measures, the subjects performed reliably better on the whole comparison than on the partial comparison. For percent errors, the mean difference was $15 \% \pm 3 \%[t(5)=4.73, p<.005]$; for correct RTs, the mean difference was $123 \pm 21 \mathrm{msec}[t(5)=5.7$, $p<.005$ ]

\section{Discussion}

The whole advantage occurred for correct RTs for both sets of stimuli. It also occurred for accuracy for the perturbed lines, but was only marginally reliable for the closed figures. The whole advantage may have been reduced because performance improved for the partial comparisons, relative to whole comparisons, perhaps because the parts were very obvious (see Palmer, 1974, 1977).

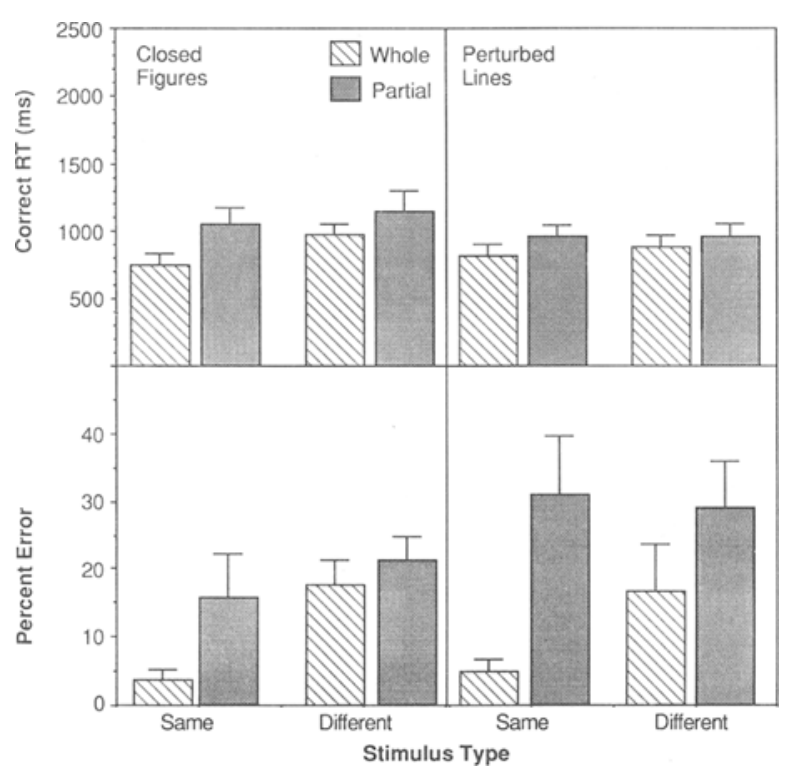

Figure 7. Experiment 2: Mean percent errors and correct RTs for same and different trials of whole and partial comparisons. The results for the closed figures are shown in the left column; the results for the perturbed line figures are shown in the right column.
Experiment 2 also allowed us to assess the effect of the distractors or the different stimuli on the task. The distractors for each set of stimuli were created in different ways. Specific rules were followed for the original set used in Experiment 1 and the closed figures, but the construction of the distractors for the perturbed lines had much more leeway. The fact that the effect occurred with several classes of distractors makes it less likely that the similarity or dissimilarity of the distractors to the study stimuli is the sole cause of the whole advantage.

Results from Experiments 1 and 2 indicate that the whole advantage occurs with three sets of two-dimensional line drawings and can be generalized to this type of letterlike stimuli. We have not tested other types of stimuli, such as the angular shapes of Cooper (1976) or the naturalistic drawings Biederman (1987) used to investigate object recognition. Nor have we tested figures, such as those used by Reed and Johnsen (1975), where the creation of the stimuli is contingent on including the parts that can be "seen" in different ways. Use of these other types of stimuli to investigate the whole advantage would establish the boundary conditions for the effect.

\section{EXPERIMENT 3 Order of Partial Comparisons}

Partial comparisons can be done in two orders: the whole-part order, when the study stimulus has the larger number of line segments, and the part-whole order, when the study stimulus has the smaller number of line segments. The order of the partial comparison has been found to make a difference in performance in other tasks that investigate parts and wholes. The part-whole order was superior to the whole-part order in both Reed and Johnsen's (1975) study and Palmer's (1979) study. However, neither of those studies systematically investigated the difference between partial and whole comparisons. Therefore, it is possible that the partial comparison done in partwhole order will yield performance equivalent to that of the whole comparison. This result would provide evidence against hierarchical representation.

The part-whole order also eliminates much of the uncertainty of the partial comparison, relative to the whole comparison. In this order, the part and its location are known before the comparison, so any uncertainty as to which part will be tested is gone. If the sole cause of the whole advantage is more uncertainty in the partial comparisons, then the part-whole order should not yield a whole advantage.

Both orders of the partial comparison are tested against whole comparisons in Experiment 3, as illustrated in Figure 8. The left column illustrates the two types of partial comparison; the right column illustrates the whole comparison. The part-whole order is illustrated in the top panel, in which the study stimulus is a three-segment figure and the test stimulus is a six-segment figure. The whole-part order is illustrated in the bottom panel, in 
PARTIAL COMPARISON

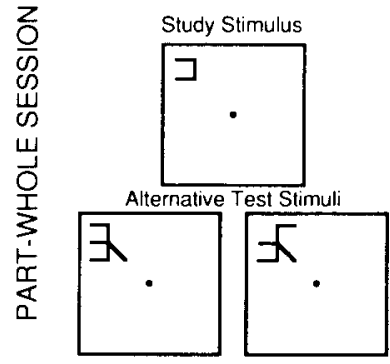

WHOLE COMPARISON

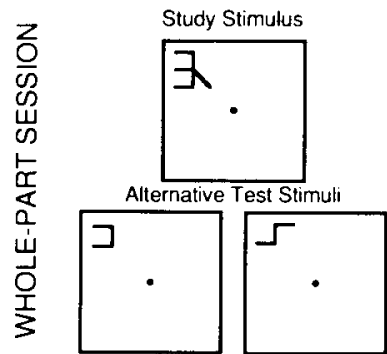

Figure 8. Conditions for Experiment 3 (both versions). The version with the part -whole order of the partial comparison is shown in the top portion; the whole-part order version is shown in the bottom portion.

which the study stimulus is a six-segment figure and the test stimulus is a three-segment figure. The whole comparisons are now between two three-segment figures instead of two six-segment figures as in Experiment 1.

\section{Method}

Experiment 3 consisted of two sessions. Each included both whole and partial comparisons. In the first session, the partial comparisons were done in the part-whole order; in the second session, the partial comparisons were done in the whole-part order (see Figure 8). In both sessions, the whole comparisons were between threesegment figures. The study stimulus appeared for $150 \mathrm{msec}$. All other aspects of Experiment 2 were identical to Experiment 1. Six subjects participated in 384 trials each.

\section{Results}

Part-whole order. As shown in Figure 9, the subjects were more accurate and faster on the whole three-segment comparisons than on the three-segment to six-segment partial comparison. For both measures, the difference between whole and partial comparisons was reliable with subjects performing better on the whole comparison than on the partial comparison. For percent errors, the mean difference was $4 \% \pm 2 \%[t(5)=2.91, p<.025]$; for correct RTs, the mean difference was $165 \pm 61 \mathrm{msec}$ $[t(5)=2.71, p<.025]$.

Whole-part order. The subjects were also more accurate and faster on the whole three-segment comparisons than on the six-segment to three-segment partial comparison. For both measures, the difference between whole and partial comparisons was reliable with subjects performing better on the whole comparison than on the partial comparison. For percent errors, the mean difference was $12 \% \pm 2 \%[t(5)=5.02, p<.005]$; for correct RTs, the mean difference was $433 \pm 88 \mathrm{msec}[t(5)=4.94$, $p<.005]$,

Order effects. The whole comparisons did not differ between the two sessions, but the whole-part ordering of the partial comparisons yielded significantly worse accuracy than did the part-whole ordering, as shown by the significant interaction $[F(1,5)=8.8, p<.05]$. The mean difference between the whole-comparison conditions was $1 \% \pm 1 \%$; the mean difference between the partial conditions was $6 \% \pm 2 \%$.

For RTs, the subjects performed faster on the whole comparisons in the part-whole order session than on the whole comparisons in the whole-part order session, with a mean RT difference of $84 \pm 34$ msec. For partial comparisons, the subjects were also significantly faster on the part-whole ordering than on the whole-part ordering, with a mean difference of $172 \pm 77 \mathrm{msec}$. However, the partial-comparison mean difference was significantly larger than the whole-comparison difference, as shown by the significant interaction $[F(1,5)=7.71, p<.05]$.

\section{Discussion}

The whole advantage occurred for both orders of the partial comparison. These results support hierarchical representation, which predicts that whole comparisons should have an advantage over partial comparisons, regardless of the order of the comparison. For example, assume hierarchical representation with top-down processing. For partial comparisons, the comparison is between the top node of one representation and a lower node of the other.

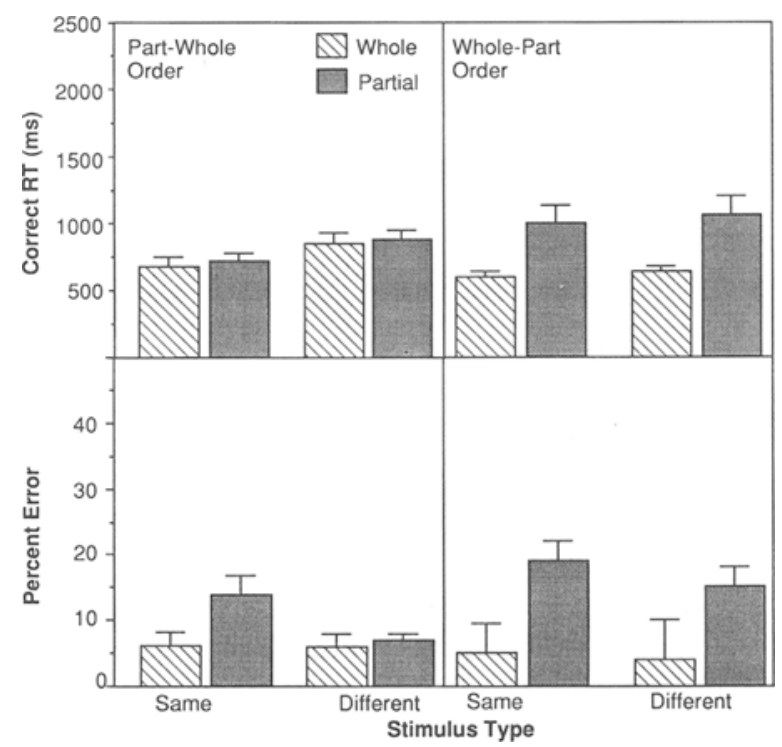

Figure 9. Experiment 3: Mean percent errors and correct RTs for same and different trials of whole and partial comparisons of both versions of Experiment 3. The results for the part-whole version are shown in the left column; the results for the whole-part version are shown in the right column. 
It does not matter which representation is of the study and which is of the test. As long as the lower nodes must be accessed on one of the representations, the task will be harder.

Partial comparisons in the part-whole order were superior to the partial comparisons in the whole-part order. This could be due to reduced uncertainty in the partial comparisons for that order. Having the part as the study stimulus reduces uncertainty by giving the subject exact information about the location of the part to be compared in the test stimulus (Palmer, 1979). Within a hierarchical representation, the subject would know which node to access and would not have to search for the appropriate one.

Experiment 3 also allowed us to investigate a possible confound in the previous experiments. In Experiments 1 and 2, different test stimuli were used in the whole- and partial-comparison conditions. For the whole comparisons, the test stimulus was a six-segment whole; however, for the partial comparisons, the test stimulus was a threesegment part. While every effort was made to use comparable distractors, no control is perfect. In Experiment 3, this possible confounding at test was avoided in the whole-part order condition by using a test stimulus that was always a three-segment figure. Thus, the distractors were identical for the whole and partial comparisons. Because the whole advantage occurred when the test stimuli were identical for both types of comparison, the whole advantage is not due to noncomparable distractors on whole versus partial comparisons.

\section{EXPERIMENT 4 Two Wholes}

To find the whole advantage, performance must be limited by some aspect of the paradigm; otherwise, subjects could perform perfectly in any condition. In Experiments 1,2 , and 3 , performance was limited by using briefduration study stimuli, which are considered to affect perception more than other processes, such as memory. If it takes longer to perceive parts than to perceive wholes, for example, then brief study durations may interfere more with perception of parts than with perception of wholes. If this is the cause of the whole advantage, then leaving the study display on for a longer duration should decrease the effect. One argument against this explanation is that Palmer (1979) found the whole advantage when he used study displays of $1 \mathrm{sec}$, which is 20 times longer than the duration used in our Experiment 1.

If the effect is due to hierarchical representation, the duration of the study display should not matter as long as the duration is long enough to encode the stimuli. We tested this idea in Experiment 4. Here, the perceptual limitation was replaced by a memory limitation. This was accomplished by increasing the number of to-be-remembered items. Instead of one figure as the study stimulus, there were two. Only one figure was tested with either a whole or a partial comparison; the subjects did not know which figure or type of comparison would occur from trial to trial. To compensate for this additional memory load, the duration of the study display was increased to $500 \mathrm{msec}$. If the whole advantage is due to perceptual processes that were limited by brief study durations, then no whole advantage would be expected in this memory variation of the task.

\section{Method}

As shown in Figure 10, the study display consisted of two sixsegment figures. The subjects did not know on which of the two study stimuli they would be tested. In the whole-comparison condition, the test display consisted of one six-segment figure; in the partial-comparison condition, the test display consisted of a threesegment part of one of the six-segment figures. Therefore, the test could be a whole or partial comparison of either study stimulus. The study stimuli appeared for $500 \mathrm{msec}$, and the test appeared in the same location as the study. This procedure differed from Experiment 1 in the number of objects, duration, and invariance of location between study and test displays. Six subjects participated in 96 trials each.

\section{Results}

As shown in Figure 11, for both measures, the difference between whole and partial comparisons was reliable with subjects performing better on the whole comparison than on the partial comparison. For percent errors, the mean difference was $20 \% \pm 5.5 \%[t(5)=3.7$, $p<.01$ ]; for correct RTs, the mean difference was $410 \pm$ $71 \mathrm{msec}[t(5)=5.7, p<.005]$.

Identical test control. A replication of Experiment 4 was done to avoid the confound of having different test stimuli for whole and partial comparisons, as discussed in Experiment 3. In this replication, the study stimuli consisted of one six-segment figure and one three-segment figure. The subjects did not know which stimulus would be tested. The test stimulus was always a three-segment figure. All other aspects of the experiment were the same as Experiment 4. Six subjects participated in 96 trials

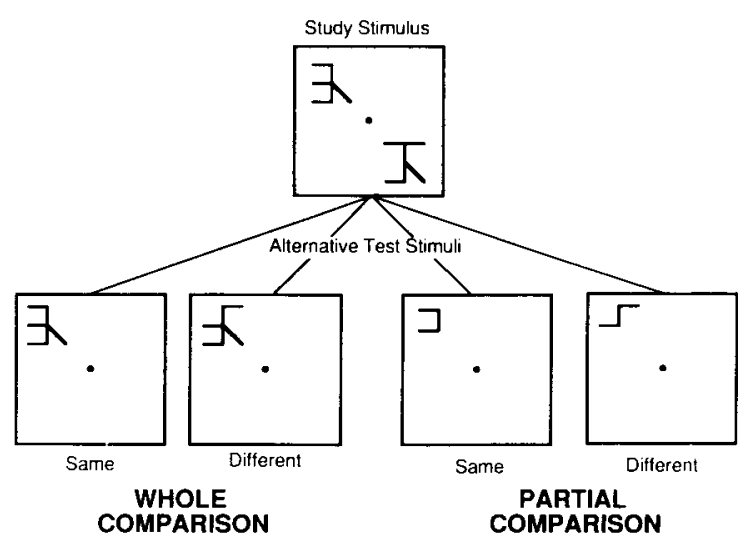

Figure 10. Experiment 4 conditions. The study stimulus was always two whole six-segment figures. In the whole-comparison condition, the test was one of the six-segment study figures or its sixsegment distractor. In the partial-comparison condition, the test was either a three-segment part of one of the study figures or its threesegment distractor. 


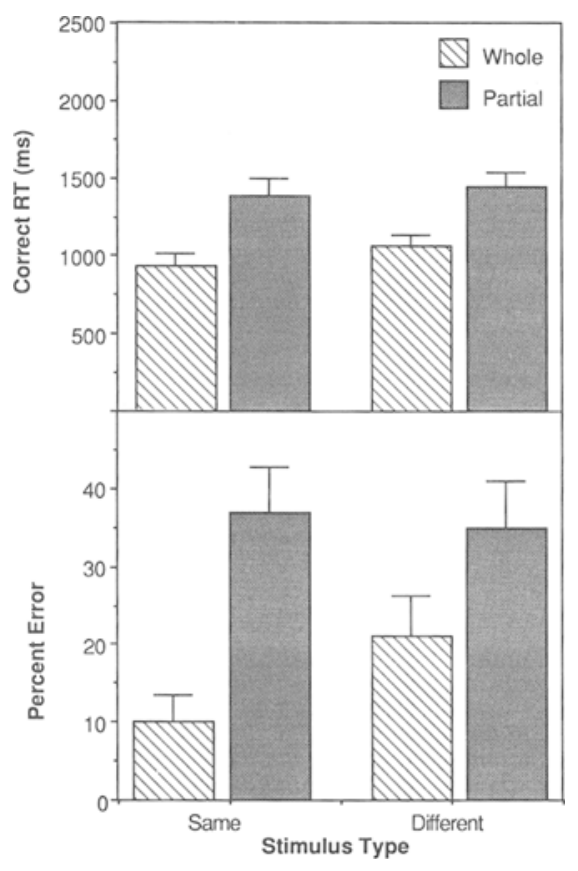

Figure 11. Experiment 4: Mean percent errors and correct RTs for same and different trials of whole and partial comparicons.

each. For both measures, the difference between whole and partial comparisons was reliable with subjects performing better on the whole comparison than on the partial comparison. For percent errors, the mean difference was $20 \% \pm 2.4 \%[t(5)=8.3, p<.001]$; for correct RTs, the mean difference was $459 \pm 79 \mathrm{msec}[t(5)=5.8$, $p<.001]$. Detailed results are shown in Table 1. This provides further evidence that the cause of the whole advantage cannot be a difference in test stimuli between whole and partial comparisons.

\section{Discussion}

The whole advantage occurred with this memory version of the task, as well as with the brief-duration versions. In Experiments 1-3, the limiting condition was brief-duration study displays that may have affected perception of the stimuli; however, in Experiment 4, a longer study duration was used, and the whole advantage was found when there were two study items. Finding the whole advantage in these two versions of the task suggests that the findings are not due to the limiting conditions employed but rather are due to the difference between wholes and parts.

\section{EXPERIMENT 5 Forced Choice}

The whole advantage might arise from the comparison process employed in the same/different tasks used in Experiments 1-4. For example, in word priority studies, the whole-word advantage increases as the number of letters in the word increases. This has been interpreted as an ef- fect of the comparison process in same/different tasks (Sloboda, 1977). For such a task, consider what constitutes a same stimulus pair. In a whole comparison, the test is identical to the study stimulus, whereas, in a partial comparison, the test stimulus is one of several subsets of the study stimulus. In our task, this could be either of two possible three-segment test parts. Therefore, in whole comparisons, there is only one possible same stimulus, whereas, in the partial comparisons there are two. For the subject, then, the mapping of alternatives onto responses is one-to-one for whole same comparisons, whereas the mapping is many-to-one for partial same comparisons (see Farell, 1985). This means that partial comparisons are more uncertain than are whole comparisons in terms of the possible stimulus alternatives. This type of uncertainty is in addition to the uncertainty that may occur when accessing the representation of the stimulus for partial comparisons, as discussed in Experiment 1.

This uncertainty hypothesis does not need to describe the nature of the representations that are being compared. The representation could be anything from an unstructured set of components to a hierarchical representation. Hierarchical representation, however, provides a parsimonious framework for these comparison differences. In this framework, whole comparisons are absolute congruence tests between the top nodes of the study and test representations. Partial comparisons are more uncertain because there are more possible comparisons to be made between the lower level nodes that represent the parts.

To investigate whether or not this aspect of the comparison process is the cause of the whole advantage, in Experiment 5, we changed the task to a two-alternative forced-choice judgment between the same and different test alternatives. The forced-choice task adds information to the comparison. Because subjects are confronted with both same and different stimuli at test, the change in the different stimulus is explicit. This is not the case in the same/different task, where the subject does not know if the test stimulus is same or different, or what the difference might be.

This added information in the forced-choice task may benefit partial comparisons more than whole comparisons. Partial comparisons are more uncertain than whole comparisons, because there is more than one possible same test stimulus for any partial comparison. When same and different stimuli are displayed together, the location and the nature of the change are known. If this information can be used, it may reduce the uncertainty in the partial comparison. If uncertainty in partial comparisons contributes to the whole advantage found in the same/different task, then use of this procedure should reduce the magnitude of the whole advantage.

\section{Method}

In this task, the study display is always a six-segment whole. The test display consists of both the same and the different alternatives for either a whole or a partial comparison. The two alternatives differ by a single line segment in four cases and by two line segments in all other cases. 
Apparatus. Experiment 5 used an apparatus different from that used in the other experiments. The displays were viewed from $78 \mathrm{~cm}$ through a $15-\mathrm{cm}$ aperture reduction screen that was $15 \mathrm{~cm}$ in front of the display. This resulted in a viewing area of about $14^{\circ}$ of arc in diameter; each figure subtended an area of $1^{\circ} \times 1^{\circ}$.

Stimuli. A different subset of the stimuli introduced by Palmer (1977) were used to provide complete counterbalancing. By this construction, each whole served as both a study stimulus and a distractor for two other study stimuli. Otherwise, these stimuli conformed to the same criteria as those used in Experiment 1.

Procedure. Figure 12 illustrates that, in each trial, the study stimulus appeared in the center of the screen for $50 \mathrm{msec}$. It was immediately followed by a blank screen for $750 \mathrm{msec}$, and then by the test stimuli. The test stimuli appeared side by side, centered in the screen and separated by $5^{\circ}$. For partial comparisons, the two parts appeared in grids that were positioned as were the whole stimuli. The alternatives remained on the screen until the subject responded by pressing either the right or the left mouse button to indicate on which side the matching stimulus appeared. There were equal numbers of trials on which the correct alternative appeared on the right and the left. Whole and partial comparisons were blocked. Auditory feedback was given after each trial. The subjects were instructed to respond accurately, with no speed stress. Six subjects participated in 512 trials each.

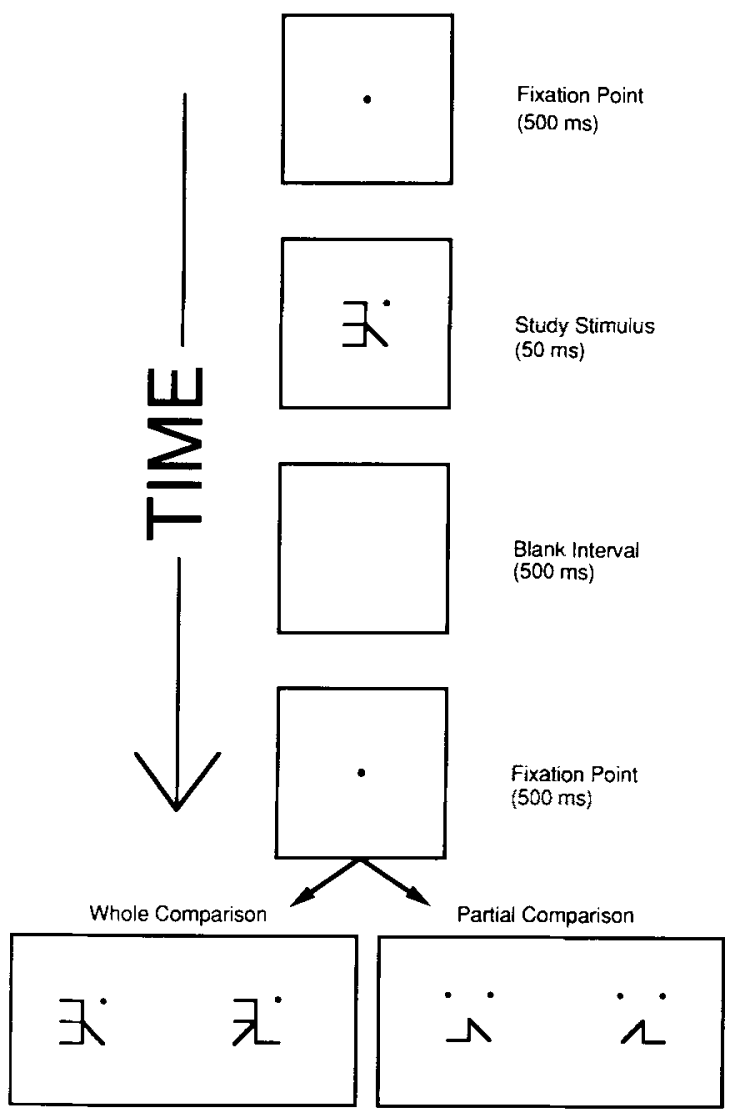

Figure 12. Experiment 5 conditions. The study stimulus was always a six-segment figure. In this forced-choice task, the test display consisted of both the same and the different alternatives for either whole or partial comparisons.

\section{Results}

The subjects were more accurate on whole comparisons (mean percent error was $3 \% \pm 1 \%$ ) than on partial comparisons (mean percent error was $18 \% \pm 2 \%$ ). The mean difference of $15 \% \pm 2 \%$ was reliable $[t(5)=8.57$, $p<.005]$.

\section{Discussion}

The whole advantage was found for accuracy in this two-alternative forced-choice procedure. This generalizes the results found with the previous same/different tasks to a second type of comparison task. These results rule out the uncertainty hypothesis. By this hypothesis, the only thing that matters is the number of possible comparisons. The forced-choice task reduces the number of comparisons to one for both whole and partial comparisons. This hypothesis predicts no whole advantage for forced-choice tasks and, thus, can be rejected. This provides further evidence that the whole advantage lies not in some aspect of the comparison but in the difference between parts and wholes.

\section{EXPERIMENT 6 Connectedness}

In Experiments 1-5, there was a troubling difference between whole and partial comparisons. The whole advantage may occur simply because study and test have more line segments in common for whole comparisons than for partial comparisons. Perhaps the more segments in common between two stimuli, the more likely they will be perceived as being similar (Palmer, 1978; Rumelhart \& Siple, 1974). Because a part and a whole cannot have as many common pieces as can two wholes, part-whole similarity is less than whole-whole similarity. By this similarity hypothesis, whole comparisons should be easier than partial comparisons.

Also, it could be that comparing figures that are not entirely identical is more difficult than comparing figures that are identical (Posner \& Mitchell, 1967). Even though a part may be physically identical to part of the object, it is not identical to the whole object. Whole comparisons depend on a conjunctive definition of same in which all elements must be physically identical. Partial comparisons depend on a disjunctive criterion in which not every line segment can be identical, because some are missing. Therefore, judgments about whole same stimuli are absolute congruence tests between two representations, whereas partial comparisons are relative tests between two representations (see Farell, 1985). This identity hypothesis provides a second possible account of the whole advantage without any explicit representation of parts and wholes.

In Experiment 6, these hypotheses were tested with a new stimulus type. These new stimuli were created by dividing each of the six-segment figures into two disconnected three-segment figures. For both kinds of stimuli, 
the whole comparison is based on all six line segments at both study and test, whereas the partial comparison is based on six at study and three at test. The similarity and the identity hypotheses predict the whole advantage for both connected and unconnected stimuli.

What is the prediction of the hierarchical hypothesis for the unconnected stimuli? If the entire unconnected figure is represented by the top node of a hierarchy, then the whole advantage should occur for the unconnected stimuli. By this scene-based hierarchical hypothesis the relevant stimulus is the scene. Alternatively, if each of the unconnected figures is separately represented by the top node of two different hierarchies, then the whole advantage should not occur for the unconnected stimuli. By this object-based hierarchical hypothesis, the relevant stimulus is the object. Experiment 6 tested the relevant stimulus for the whole advantage.

In summary, three hypotheses predict that the whole advantage will be found for unconnected, as well as connected, stimuli, whereas only the object-based hierarchi-
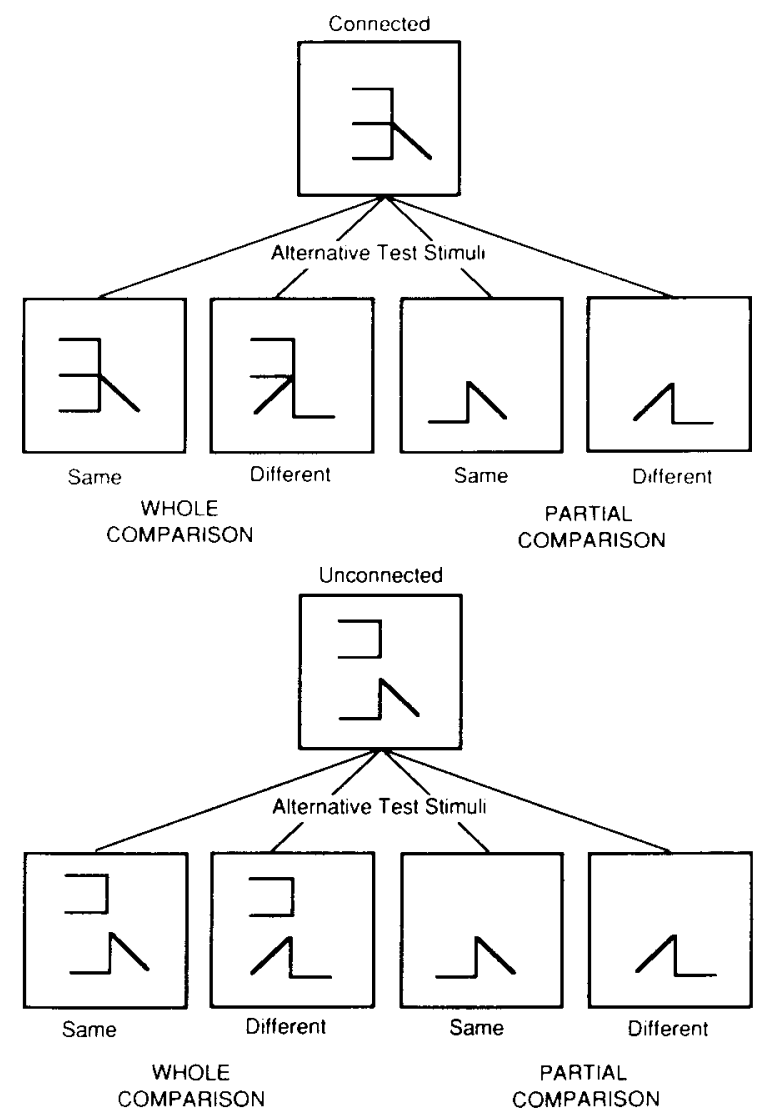

Figure 13. Experiment 6 conditions. The study stimulus was either one connected six-segment figure or one unconnected six-segment figure split into two three-segment parts. The whole-comparison test figure always consisted of six segments; the partial-comparison test figure always consisted of three segments.

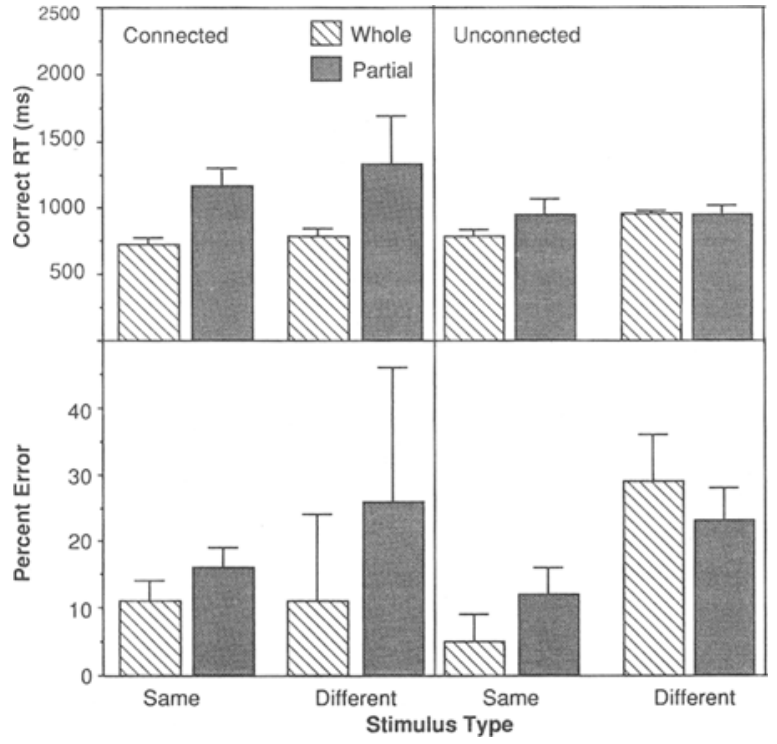

Figure 14. Experiment 6: Mean percent errors and correct RTs for connected (top) and unconnected (bottom) ngures for same and different trials of whole and partial comparisons.

cal hypothesis predicts that the whole advantage will be found for the connected stimuli, but not for the unconnected stimuli.

\section{Method}

Two factors were manipulated: the connectedness of the figures and the type of comparison. As shown in Figure 13, the study stimuli consisted of either a six-segment whole or a six-segment whole split into two three-segment pieces that were both displayed. Thus, there were two types of study stimuli: the connected stimuli, which consisted of the six-segment wholes, and the unconnected stimuli, which consisted of the six-segment wholes split into two three-segment figures. In each trial, there was only one study stimulus, which was either connected or unconnected. As in Experiments 1-5, there were two conditions at test: the whole comparison, in which the test had six segments, and the partial comparison, in which the test had three segments. Each trial used either connected or unconnected stimuli; they were never mixed within a trial. In other respects, the procedure was the same as Experiment 1 , which is essentially replicated in the connected condition. Six subjects participated in 192 trials each.

\section{Results}

Results for both the connected and unconnected stimuli are shown in Figure 14. For the connected stimuli, the subjects performed reliably better on the whole comparisons than on the partial comparisons. For percent errors, the mean difference was $21 \% \pm 8 \%[t(5)=2.94$, $p<.025]$; for correct RTs, the mean difference was 367 $\pm 113 \mathrm{msec}[t(5)=3.24, p<.025]$. For the unconnected stimuli, there were no reliable differences for either accuracy or correct RTs [percent mean difference, $0 \% \pm 3 \%, t(5)=0, p>.05$; mean correct RT difference, $88 \pm 89 \mathrm{msec}, t(5)=.98, p>.05]$. The whole ad- 
vantage was reliably larger for the connected stimuli than for the unconnected stimuli, as shown by the significant interaction between stimulus type and comparison condition on both accuracy $[F(1,5)=10.86, p<.03]$ and correct $\operatorname{RTs}[F(1,5)=72.33, p<.001]$.

\section{Discussion}

Experiment 6 showed that whole advantage did not always occur; it vanished for the unconnected stimuli. This is evidence against the similarity, identity, and scenebased hierarchical hypotheses. The whole advantage does not depend solely on the number of segments involved in the comparison or on the whole comparison being an identity match. It does depend on the whole being a connected object.

These results support the object-based hierarchical hypothesis. By this hypothesis, the whole advantage is due to an object-related processing system, such as a hierarchical representation, with the uppermost node representing a whole object. Because the unconnected stimuli are not encoded as single objects, there is no whole advantage.

Alternatively, a scene-based hierarchy is compatible with these results if objects enjoy a processing advantage. For example, assume a hierarchy that represents the entire scene at the top level, individual objects at the next lower level, and parts at the next lower level. Furthermore, assume that nodes in the hierarchy can be accessed directly at the object level, but lower levels must be accessed by a sequential top-down process. By this account, the whole advantage occurs in Experiment 1, because the part node cannot be accessed directly. The whole advantage does not occur for the unconnected objects in Experiment 6 , because the unconnected three-segment figures are both represented as objects, not as parts. For these stimuli, the whole comparisons involve scenes and the partial comparisons involve objects, and, for either comparison, the relevant node can be directly accessed.

\section{GENERAL DISCUSSION}

A whole advantage was found: For connected objects, the subjects were faster and more accurate in the wholecomparison condition than in the partial-comparison condition. Correct RT mean differences were reliably in the predicted direction for 12 out of 12 measurements. Percent correct mean differences were reliably in the predicted direction for 12 out of 13 measurements and were marginally reliable in the predicted direction for the remaining measurement. The effect is robust.

\section{Interpretation}

Relevant stimulus. What is the relevant stimulus for producing the whole advantage? Experiment 2 ruled out differences specific to the figures themselves, since the advantage occurred for two other stimulus sets. Experiment 3 ruled out differences specific to three- or sixsegment figures. Experiment 6 ruled out the possibility that the whole advantage was to whole comparisons involving more segments in common than partial comparisons, because it was not found for unconnected stimuli.

The effect was found with connected figures and not with otherwise identical unconnected figures. Thus, one condition for this effect is partial and whole comparisons of connected figures. This result is analogous to the finding that extra letter spacing in words eliminates the word superiority effect (Mewhort, Marchetti, \& Campbell, 1982).

Processing locus. The processing locus of the whole advantage can be narrowed to some extent. The critical process cannot be limited to certain processing loci, such as selective masking, in the way that it can with the word superiority effect. It cannot be due to specific perceptual and performance-limiting effects, such as brief-duration study stimuli, since they were also found with longer durations and greater memory load. It cannot be due solely to partial comparisons' having more uncertainty than whole comparisons, because the whole advantage was found with two procedures that should have eliminated much of the uncertainty (the part-whole order of the partial comparison in Experiment 3, and the forced-choice procedure of Experiment 5). The whole advantage cannot be due to the specific comparison task used, since it was found with both same/different and forced-choice tasks. It cannot be due to comparison processes that depend on similarity or identity differences between whole and partial comparisons, because it did not occur for unconnected stimuli.

Generality. The whole advantage was established by both differences in RTs and accuracy. It occurred without masking and with short durations, as well as with memory load and long durations. These effects were analogous to those found for words and letters in the word priority studies. For accuracy, these effects were not analogous to word superiority effects, which occur only with certain masking stimuli (e.g., Johnston \& McClelland, 1980) or other stimulus degrading procedures, such as luminance reduction or direct feature removal (Marchetti \& Mewhort, 1986). For latency, the whole advantage may be more analogous to findings in the word superiority paradigm, since word superiority for RTs has been found without masking (e.g., Johnson, 1975; Krueger, 1970, 1989; Polf, 1976). A comparison with object superiority effects is more ambiguous because, although object superiority effects occur without masking, they do not occur with RT measures (Klein, 1978).

That the whole advantage is robust is not surprising, either intuitively or in light of the findings in the word priority literature. Word priority is commonly found without masking, and it occurs with pronounceable nonwords, as well as words (Johnson et al., 1986). One of the few ways to make word priority fail is to use simultaneous presentation (Marmurek, 1986; Umansky \& Chambers, 1980). Marmurek argued that this is because, in simultaneous partial comparisons, words are perceived 
as individual letters rather than as words. Therefore, it appears that word priority is also due to a different treatment of wholes and parts.

\section{Alternative Hypotheses}

All of our results are consistent with a hierarchical representation of objects coupled with top-down processing at retrieval, as postulated by Palmer $(1974,1977$, 1979). In this model of hierarchical representation, processing of any comparison proceeds sequentially in a topdown fashion, starting with an evaluation of the topmost object node and continuing through the lower level part nodes of the hierarchy until either an upper or a lower comparison threshold is exceeded. Exceeding the upper threshold indicates a close match demanding a "same" response; exceeding a lower threshold indicates a very different stimulus demanding an immediate "different" response. In other words, the comparison process is sequential, top-down, and self-terminating. This top-down processing hypothesis predicts the whole advantage, because partial matches can only be accurately made at lower levels of the hierarchy and whole matches can be sometimes made at the top level of the hierarchy. Other examples of processing differences that can produce a whole advantage can be found in discussions of dual process models of the word and object superiority paradigm (Klein, 1978; Marchetti \& Mewhort, 1986).

A variant of this model postulates that only the object is at first explicitly represented, unless and until the explicit representation of the parts is needed. Only when explicit part information is needed is further processing of the object representation done, with the result being a hierarchical representation of the object and of its parts. In this model, partial matches are harder, because whole comparisons can be done with already-represented information, whereas further processing must be done to create the part representations for comparison. This is in contrast to the previous explanation, which places the further processing at retrieval.

A more subtle hierarchical hypothesis places the source of the whole advantage in a mismatch between the experimenter's chosen part and the part that is represented in the subject's hierarchy. In other words, the part chosen by the experimenter is invalid as a psychological representation. Consider this invalid part hypothesis in connection with a hierarchical representation in which all processing is the same for wholes and parts. That is, retrieval and comparison processes would not be top-down but would be able to access any node in the hierarchy as quickly and as well as any other node. In this case, the effect arises only because the parts used by experimenters do not match the parts that are represented in the subject's hierarchy. Therefore, the stimulus part has no corresponding part node in the subject's hierarchy, and some further comparison process must be invoked. This is not a problem for whole-object comparisons because the experimenter's objects probably do correspond to the subject's object representations. This hypothesis can account for the lack of a whole advantage with the unconnected stimuli in Experiment 6. For these stimuli, there should have been no mismatch between the experimenter's parts and the subjects' representations, due to the obviousness of the three-segment figures. Thus, the whole advantage may be an artifact of the specification of the stimuli. An argument against this hypothesis is that it would not predict a word priority effect as long as letters are the represented parts. For this reason, we do not think the invalid part hypothesis can be the entire explanation for the whole advantage. There is evidence that the representation of parts has consequences for behavior. Palmer $(1974,1977)$ found that subjects were very consistent in parsing objects into parts. When asked to divide a line figure into two components, subjects behaved in accordance with the predictions of his part goodness model. In addition, he found that subjects were better at tasks, such as part verification and mental synthesis, when using objects with good parts rather than poor parts. Similarly, Bower and Glass (1976) found that subjects were better able to recall nonsense line drawings when cued with good parts than when cued with poorer parts. In summary, these studies suggest that some stimulus parts are explicitly represented, and others are not.

The whole advantage is also predicted by the hypothesis that emergent features exist for whole objects that do not exist for any of its parts. Such a difference may be due to these additional features arising out of the relations between the parts (Lanze, Maguire, \& Weisstein, 1985; Pomerantz, Sager, \& Stover, 1977; Treisman \& Paterson, 1984). For example, the sides of a square form a closed figure together, but not separately. When a figure is broken into parts, emergent features may be disturbed, and the representation of the parts will not include all of the emergent features of the whole. By such an emergent features hypothesis, the lack of emergent features in the parts makes partial matches more difficult than whole matches. Whenever a difference is detected during a partial comparison, it is not immediately clear whether the discrepancy is due to a part/whole mismatch or a missing emergent feature. This hypothesis can also account for the results of Experiment 6, because the unconnected wholes may not have had the emergent features of the connected wholes and, therefore, would not be expected to yield a whole advantage. This hypothesis does not specify the nature of the memory representation, and, although it certainly could occur with hierarchical representation, it does not depend on it.

We suspect that, depending on circumstances, all three of these mechanisms contribute to the whole advantage.

\section{Conclusion}

Whole comparisons were faster and more accurate than were partial comparisons for a variety of stimuli and tasks. These findings provide further support for the hypothesis that the hierarchical relation between wholes and parts is retained in memory representations. Hierarchical representation allows both the whole and the parts of 
an object to be available for comparison to memory. Additionally, the organization of the parts in relation to each other and to the whole is efficiently represented. Such a representation seems a logical candidate, given the requirements of the recognition process and the results of these studies.

\section{REFERENCES}

Biederman, I. (1987). Recognition-by-components: A theory of human image understanding. Psychological Review, 94, 115-147.

BOWER, G. H., \&lass, A. L. (1976). Structural units and the redintegrative power of picture fragments. Journal of Experimental Psychology: Human Learning \& Memory, 2, 456-466.

COOPER, L. A. (1976). Individual differences in visual comparison processes. Perception \& Psychophysics, 19, 433-444.

ERIKSEN, C. W., Schultz, D. W. (1979). Information processing in visual search: A continuous flow conception and experimental results. Perception \& Psychophysics, 25, 249-263.

FARELL, B. (1985). "Same"'-"Different' judgments: A review of current controversies in perceptual comparisons. Psychological Bulletin, 98, 419-456.

Hoffman, D. D., \& Richards, W. A. (1984). Parts of recognition. Cognition, 18, 65-96.

JoHNSON, N. F. (1975). On the function of letters in word identification: Some data and a preliminary model. Journal of Verbal Learning \& Verbal Behavior, 14, 17-29.

Johnson, N. F., Turner-LygA, M., \& Pettegrew, B. S. (1986). Partwhole relationships in the processing of small visual patterns. Memory \& Cognition, 14, 5-16.

Johnston, J. C., \& MCClelland, J. L. (1980). Experimental tests of a hierarchical model of word identification. Joumal of Verbal Learming \& Verbal Behavior, 19, 503-524.

KINCHLA, R. A., \& Wolfe, J. M. (1979). The order of visual processing: "Top-down," "bottom-up," or "middle-out." Perception \& Psychophysics, 25, 225-231.

KLEIN, R. (1978). Visual detection of line segments: Two exceptions to the object superiority effect. Perception \& Psychophysics, 24, 237-242.

KRUEGER, L. E. (1970). Search time in a redundant visual display. Journal of Experimental Psychology, 83, 391-399.

KRUEGER, L. E. (1989). Detection of intraword and interword letter repetition: A test of the word unitization hypothesis. Memory \& Cognition, 17, 48-57.

Lanze, M., Maguire, W., \& Weisstein, N. (1985). Emergent features: A new factor in the object-superiority effect? Perception \& Psychophysics, 38, 438-442.

MarchetT, F. M., \& Mewhort, D. J. K. (1986). On the wordsuperiority effect. Psychological Research, 48, 23-35.

Marmurek, H. H. C. (1977). Processing letters in words at different levels. Memory \& Cognition, 5, 67-72.

MARMUREK, H. H. C. (1986). Whole and part comparisons of words and nonwords. Memory \& Cognition, 14, 113-123.

MARR, D., NishimARA, H. K. (1978). Representation and recognition of the spatial organization of three-dimensional shapes. Proceed ings of the Royal Society of London, B, 200, 269-294.

MARTIN, M. (1979). Local and global processing: The role of sparsity. Memory \& Cognition, 7, 476-484.
Mewhort, D. J. K., Marchetti, F. M., \& Campbell, A. J. (1982). Blank characters in tachistoscopic recognition: Space has both a symbolic and a sensory role. Canadian Journal of Psychology, 36, 559-575.

MILLER, J. (1981). Global precedence in attention and decision. Journal of Experimental Psychology: Human Perception \& Performance, 7, 1161-1174.

NAvon, D. (1977). Forest before trees: The precedence of global features in visual perception. Cognitive Psychology, 9, 353-383.

Navon, D. (1981). The forest revisited: More on global precedence. Psychological Research, 43, 1-32.

Palmer, S. E. (1974). Structural aspects of perceptual organization. U.M.I. Dissertation Information Service. (University Microfilms No. $75-11,232$ )

Palmer, S. E. (1977). Hierarchical structure in perceptual representation. Cognitive Psychology, 9, 441-474.

Palmer, S. E. (1978). Structural aspects of visual similarity. Memory \& Cognition, 6, 91-97.

PAlMER, S. E. (1979). Organization of figures in perception and memory. Unpublished manuscript.

PoLF, J. O. (1976). The word superiority effect: A speed-accuracy analysis and test of a decoding hypothesis. Unpublished doctoral dissertation, University of Oregon, Eugene.

Pomerantz, J. R., Sager, L. C., \& Stover, R. J. (1977). Perception of wholes and of their component parts: Some configural superiority effects. Joumal of Experimental Psychology: Human Perception \& Performance, $3,422-435$.

Posner, M. I., Mitchell, R. F. (1967). Chronometric analysis of classification. Psychological Review, 74, 392-409.

REED, S. K. (1974). Structural descriptions and the limitations of visual images. Memory \& Cognition, 2, 329-336.

REED, S. K., JohNSEN, J. A. (1975). Detection of parts in patterns and images. Memory \& Cognition, 3, 569-575.

Reicher, G. M. (1969). Perceptual recognition as a function of meaningfulness of stimulus material. Journal of Experimental Psychology, 81, 275-280.

Rumelhart, D. E., \& Siple, P. A. (1974). Process of recognizing tachistoscopically presented words. Psychological Review, 81, 99-118.

SLOBodA, J. A. (1976). Decision times for word and letter search: A holistic word identification model examined. Joumal of Verbal Learning \& Verbal Behavior, 15, 93-101.

SLOBODA, J. A. (1977). The locus of the word-priority effect in a targetdetection task. Memory \& Cognition, 5, 371-376.

Treisman, A., \& Paterson, R. (1984). Emergent features, attention, and object perception. Journal of Experimental Psychology: Human Performance \& Perception, 10, 12-31.

Umansky, J. A., \& Chambers, S. M. (1980). Letters and words in word identification. Memory \& Cognition, 8, 433-446.

Weisstein, N., \&ARris, C. S. (1974). Visual detection of line segments: An object-superiority effect. Science, 186, 752-755.

WheELER, D. D. (1970). Processes in word recognition. Cognitive Psychology, 1, 59-85.

Williams, A., \& WeISSTEIN, N. (1978). Line segments are perceived better in a coherent context than alone: An object-line effect in visual perception. Memory \& Cognition, 6, 85-90.

(Manuscript received October 13, 1989; revision accepted for publication March 11, 1991.) 